Published in final edited form as:

Circulation. 2015 May 19; 131(20): 1796-1803. doi:10.1161/CIRCULATIONAHA.114.010270.

\title{
Hospital Readmissions Reduction Program
}

Colleen K. Mcllvennan, DNP, ANP ${ }^{1,2}$, Zubin J. Eapen, MD, MHS ${ }^{3}$, and Larry A. Allen, MD, MHS $^{1,2}$

${ }^{1}$ Section of Advanced Heart Failure and Transplantation, Division of Cardiology University of Colorado School of Medicine, Aurora, CO

${ }^{2}$ Colorado Cardiovascular Outcomes Research Consortium, Denver, CO

${ }^{3}$ Duke Clinical Research Institute, Durham, NC

\section{Keywords}

patient readmission; heart failure; health care; health policy

Hospital readmission measures have been touted not only as a quality measure, but also as a means to bend the healthcare cost curve. The Affordable Care Act (ACA) established the Hospital Readmission Reduction Program (HRRP) in 2012. Under this program, hospitals are financially penalized if they have higher than expected risk-standardized 30-day readmission rates for acute myocardial infarction, heart failure, and pneumonia. The HRRP has garnered significant attention from the medical community, both positive and negative. Herein we describe the reasons the HRRP was implemented, the penalties levied, the impact it has had on transitional care and readmissions, the pros and cons of the policy, and its future.

\section{Historical Context}

Hospital readmissions are associated with unfavorable patient outcomes and high financial costs. ${ }^{1,2}$ Causes of readmissions are multi-factorial and rates vary substantially by institution. ${ }^{3,4}$ Historically, nearly $20 \%$ of all Medicare discharges had a readmission within 30 days. ${ }^{1}$ The Medicare Payment Advisory Commission (MedPAC) has estimated that $12 \%$ of readmissions are potentially avoidable. Preventing even $10 \%$ of these readmissions could save Medicare $\$ 1$ billion. ${ }^{5}$ Therefore, reducing hospital readmissions has been made a national priority. In 2008, MedPAC recommended to Congress that the Centers for Medicare and Medicaid Services (CMS) begin confidentially reporting readmission rates and resource usage to hospitals and physicians. ${ }^{6}$ In 2009, CMS began publicly reporting hospital-level readmission rates, which were added to the Hospital Compare website. ${ }^{7}$

Before 2012, hospitals had little direct financial incentive to reduce readmissions. For Medicare beneficiaries with inpatient stays, hospitals receive payment using the inpatient

Address for Correspondence: Larry A. Allen, MD, MHS, University of Colorado, School of Medicine, 12631 East $17^{\text {th }}$ Avenue, B130, Aurora, CO, 80045, Tel: 303-724-4713, Fax: 303-724-2094, larry.allen@ucdenver.edu.

Conflict of Interest Disclosures: None. 
prospective payment system (IPPS). This payment, based on a diagnosis-related group (DRG), covers the inpatient stay as well as any outpatient diagnostic and admission-related outpatient non-diagnostic services provided by the institution on the date of the patient's admission or within 3 days immediately preceding the date of admission. ${ }^{8}$ Notably, this payment does not include post-discharge care or interventions that would potentially reduce the incidence of readmission.

In order to provide direct financial incentive to hospitals participating in the IPPS to reduce readmission rates, the ACA added section 1886(q) to the Social Security Act establishing the HRRP. Since October 1, 2012, the HRRP has required CMS to reduce payments to IPPS-participating hospitals with excess readmissions. ${ }^{9}$ Excess readmissions are defined by measuring a hospital's readmission rates, adjusted for age, sex, and co-existing conditions, which are then compared to the national averages. ${ }^{10}$ The penalty is a percentage of total Medicare payments to the hospital; the maximum penalty has been set at $1 \%$ for $2013,2 \%$ for 2014, and 3\% for 2015. The penalties assessed to hospitals are CMS' savings. According to the ACA, the savings are added to the Medicare Hospital Insurance Trust Fund, with the goals of protecting guaranteed benefits and providing new benefits and services for all Medicare beneficiaries, in addition to lowering the cost of Part B premiums. ${ }^{11}$

The conditions initially included in the HRRP were acute myocardial infarction, heart failure, and pneumonia, which expanded in 2015 to include patients with acute exacerbation of chronic obstructive pulmonary disease and patients admitted for elective total hip arthroplasty and total knee arthroplasty. ${ }^{9}$ Conditions are identified based on primary discharge diagnosis, not the DRG assigned to the hospitalization. Additionally, hospitals must have at least 25 initial hospitalizations for a diagnosis to be measured. Public, and possibly financial, accountability is thereafter extending to hospital-wide readmission rates. ${ }^{10,12}$ The HRRP continues to refine its policies, including prior changes in the methodology to calculate the hospital readmission adjustment factor and accounting for planned readmissions.

\section{Methodology}

Risk-adjusted 30-day readmission measures are used to measure hospital performance. Endorsed by the National Quality Forum, the risk adjustment measures are based on hierarchical logistic regression models. The models were derived using Medicare claims data and validated using claims and medical record data. These claims-based models are used to calculate hospital risk-standardized 30-day all-cause readmission rates. ${ }^{13-15}$ The reported rates are similar to the Hospital Compare rates, with the exclusion of readmissions to Veterans Health Administration or critical access hospitals.

The excess readmission ratio, used to assign penalties to hospitals, adjusts for variation in hospitals' volume and case mix. Hierarchical logistic regression models are used to calculate an adjusted actual number of readmissions in the numerator and an expected number of readmissions in the denominator. ${ }^{16}$ The numerator is calculated by estimating the probability of readmission for each patient at a specific hospital. This takes into account the hospital-specific effect, the probability of readmission for each patient, and the probability 
of readmission based on patient risk factors (age, gender, and selected clinical comorbidities). These probabilities are then summed over all of a hospital's patients with the diagnosis. The denominator is calculated by summing the probabilities of readmission for each patient at an average hospital using the same regression coefficients and the average hospital effect. Therefore, the ratio calculates the total predicted readmissions at a hospital compared with the total expected readmissions if the patients were treated at an average hospital with similar patients. The threshold established to define "excess" is above the average (i.e. ratio >1.0) and any ratio above that will generate a penalty; the actual dollar amount of the penalty is then determined by calculating 1 minus the aggregate payments for excess readmissions divided by the aggregate payments for all discharges, and multiplying this "readmissions adjustment factor" by a hospital's base DRG payment. ${ }^{9}$

Hospital volume can play a significant role in the assessment of hospital performance. The assessment of quality depends on the amount of information available, meaning the fewer patients treated, the less data available; further, estimates may be more unstable for small hospitals given their lower sample size. With only three conditions included in the first two years, many hospitals were excluded due to the volume criteria. With the inclusion of more conditions in 2015, a greater number of hospitals are at risk of receiving a penalty, and the dollars at risk have increased significantly as well.

\section{Structure: Penalties Levied on Hospitals}

To fully understand the impact of HRRP, it is important to identify which hospitals are receiving penalties. In year one of the HRRP (based on data 2008-2011), 2,213 hospitals were penalized $\$ 280$ million for excessive readmission rates; approximately $30 \%$ of eligible hospitals received no penalty, $60 \%$ received a penalty of less than $1 \%$, and $10 \%$ of hospitals received the maximum penalty. ${ }^{17}$ This was about $\$ 10$ million less than originally estimated and represented $0.3 \%$ of total Medicare base payments to hospitals. In year two, 2,225 hospitals were penalized \$227 million and represented 0.2\% of total Medicare base payments to hospitals. ${ }^{17}$ In the second year 1,371 hospitals received lower penalties, whereas 1,074 hospitals received greater penalties; the average penalty decreased from $0.42 \%$ to $0.38 \% .{ }^{17}$ The majority of hospitals penalized were large hospitals, teaching hospitals, and safety-net hospitals. ${ }^{18}$ In both years, the majority of hospitals receiving penalties served low-income patients. The most recent data for year three was released in August 2014, in which 2,610 hospitals were assessed penalties. The average penalty increased from $0.38 \%$ to $0.63 \%$ with 39 hospitals receiving the maximum $3 \%$ penalty. ${ }^{19}$ One reason for the increased and extensive penalties is the addition of two conditions.

\section{Processes: Transitions of Care}

The HRRP has fueled intense interest around understanding the predictors and causes of readmission. However, the retrospective nature of diagnosis ascertainment, the relatively poor performance of readmission risk models, ${ }^{20}$ and the wide-range of causes of readmission has limited the ability of hospitals to target patients at highest risk with tailored interventions. Regardless, many hospitals have invested a large amount of time and money to implement a variety of general transitional care interventions, such as arranging early 
discharge follow-up, reconciling medications, partnering with other local hospitals or care facilities, and performing follow-up phone calls. ${ }^{21}$

The HRRP itself does not provide resources to hospitals to fund readmission reduction interventions and care redesign. However, CMS has provided additional funding for transitional care efforts through complementary programs. The Community-based Care Transitions Program (CCTP), created by Section 3026 of the ACA, aims to test models for improving care transitions and reducing readmissions. ${ }^{22}$ Notably, the CCTP directs $\$ 500$ million only to hospitals who applied and were approved; it currently includes 102 organizations. Starting January 2013, Transitional Care Management Services provided two new current procedural terminology (CPT) codes. ${ }^{23,24}$ These CPT codes cover services provided to a patient whose medical or psychosocial problems require moderate or highcomplexity medical decision making during transitions in care. This includes discharge from an inpatient hospital setting (acute hospital, rehabilitation hospital, long-term acute care hospital), partial hospital, observation status in a hospital, or skilled nursing facility, to the patient's community setting (home, domicile, rest home, or assisted living). While these codes provide a higher billing for post-discharge visits either within 7 or 14 days of discharge-depending on the code-they go to the outpatient provider and thus do not help offset HRRP penalties unless there is financial integration of inpatient and outpatient care. Similarly, CMS will begin to pay physicians for the provision of chronic care management services, further incentivizing the coordination of inpatient and outpatient care. ${ }^{25,} 26$

\section{Outcomes: Readmissions Reduction}

Early data suggest that HRRP implementation has been associated with a reduction in readmissions. According to recently released Health and Human Services data, from 2007-2011 the all-cause 30-day readmission rate among Medicare beneficiaries held relatively constant at 19.0-19.5\%; in 2012 and 2013 this rate fell to $18.5 \%$ and $17.5 \%$, respectively (Figure). ${ }^{27,} 28$ These decreasing rates translate to an estimated 150,000 fewer hospital readmissions between January 2012 and December 2013. Although these favorable trends may reflect any number of other changes occurring over this period, the temporal relationship argues that the HRRP may be meeting its intended purpose to reduce hospital readmissions and decrease CMS spending.

\section{Commentary}

The HRRP has garnered both praise and criticism. Proponents of the program highlight the overall engagement of hospitals and health care providers across the experience of illness. At the same time the program has been active, readmission rates have dropped by approximately $1 \%$ without an apparent increase in length of stay or mortality. However, there remains debate on the potential unintended consequences of readmission strategies and the potential to disproportionately penalize hospitals that care for vulnerable populations. 


\section{Pros}

\section{Focus on the Care Coordination Across Silos of Care}

The reliance on episode-based payments entrenched silos of care, where acute care hospitals were largely incentivized to get patients only well enough to leave the hospital. Transitional care, communication of care plans with outside providers and consideration of proper disposition were de-emphasized. Today these issues are front and center, with hospitals taking greater interest in events that occur outside the walls of the hospital after discharge. The HRRP has helped forge collaborative relationships-within hospitals, between medical institutions, and in surrounding communities - that focus on improving the overall patient experience through hospitalization and beyond.

The HRRP has also created awareness and collaboration at the national level. One national quality initiative, Hospital to Home (H2H), began in 2009 to improve transitions of care and reduce unnecessary readmissions. ${ }^{29}$ This joint effort between the American College of Cardiology and the Institute for Healthcare Improvement continues to provide a national clearinghouse of information and tools based upon institutions' successful interventions. Similarly, the American Heart Association's TARGET-HF program aims to improve quality, care transitions and outcomes of patients with heart failure by providing healthcare professionals with resources and materials targeting heart failure awareness, prevention, and treatment. ${ }^{30}$ The State Action on Avoidable Rehospitalizations is a multi-state initiative that engages patients, families, payers, and policy-level leaders in an effort to reduce rehospitalizations. ${ }^{31}$ Other initiatives such as Interventions to Reduce Acute Care Transfers have focused on the post-discharge environment and have aimed to reduce readmissions from skilled nursing facilities. ${ }^{32}$ The interest in successful transitional care strategies continues to grow and collaboration on a national level will assist hospitals in finding solutions that are most practical and effective. ${ }^{33}$

\section{Emphasis on Patient Outcomes Rather than a Few Care Processes}

Many quality measures used for public reporting and pay-for-performance have historically focused on individual processes of care. Properly constructed process measures have important strengths: if based upon the most robust evidence, they possess strong face validity and do not require risk-adjustment, further lending credibility and interpretability. ${ }^{34}$ However, several inherent limitations to process measures exist, including: 1) they apply only to those patients who qualify for the measure; 2) they assess only a small fraction of the processes of care that are routinely delivered; and 3) performance on many process measures can reach very high levels for all hospitals, such that they no longer discriminate among institutions. ${ }^{35}$ Most important, the relationship between quality of care as determined by process performance measures and important patient outcomes has been controversial. An analysis comparing patients who received heart failure processes of care with those who did not found that only beta blocker therapy-which is not currently used by CMS as part of the hospital quality measurement program — was associated with lower mortality, and even this one association was modest. ${ }^{36}$ Another study found that current heart failure performance measures, except for angiotensin-converting enzyme inhibitors or angiotensin receptor 
blockers prescribed at discharge, have little relationship to patient mortality or rehospitalization in the first 60 to 90 days after discharge. ${ }^{37}$

The pivot to an outcome measure highlighting risk-standardized hospital readmission rates has a number of appealing characteristics. An outcome measure, like readmission, is patientcentered with focus on what matters to patients, caregivers, payers, and society. Rather than choosing a handful of care processes from the thousands that occur during a hospitalization, outcomes measures - if carefully constructed and fairly adjusted for case mix — can better reflect the overall performance of a health system. This incentivizes providers and hospitals to emphasize care design that is felt to be most important (not only what can be easily measured), and avoids a one-size fits all approach.

\section{All-Cause Versus Disease-Specific Readmission}

The focus on all-cause readmission versus disease-specific readmission has been an area of debate. It has been reported that reasons for readmission are variable, and less often related to the condition that led to the index hospitalization. For example, in an analysis of Medicare fee-for-service data from 2007-2009, only 35\%,10\%, and 22\% of heart failure, acute myocardial infarction and pneumonia patients respectively were readmitted within 30 days for the same condition as the index hospitalization. ${ }^{38}$ The focus on all-cause readmission rates incentivizes hospitals to focus not only on the primary medical problem, but also a patient's comorbid, psychological, social, and environmental conditions. With the HRRP, hospitals have focused on transitional care measures that are aimed to improve total care delivery. Patients benefit from improved communication between inpatient and outpatient providers, a more seamless transition from hospital to home, and the potential to avoid an unnecessary hospitalization.

\section{Balancing Index Length of Stay with Readmission Risk}

One of the more striking inter-hospital differences has been variation in the length of stay for the index hospitalization. This may relate to readmission. Countries with longer length of stay for heart failure hospitalizations appear to have lower rates of readmission within 30 days. In a large contemporary acute heart failure trial conducted across 27 countries, mean length of stay ranged from 4.9 to 14.6 days (6.1 days in the U.S.). There was an inverse correlation between country-level mean length of stay and readmission $(r=-0.52) .{ }^{39}$ Similar trends were observed across U.S. study sites. Longer index hospitalizations expend more resources and keep patients from being home; yet, there appears to be a trade off in terms of readmission rates. Under the current system, IPPS-DRG-based reimbursement incentives are complemented by the HRRP, balancing a desire to limit unnecessarily long hospital stays while still discouraging unnecessary readmissions due to premature discharge.

\section{Shifting Away from Fee-For-Service Model}

For the first time, Medicare has set specific goals for alternative payment models and valuebased payments. By 2016, Medicare seeks to have $85 \%$ of all Medicare fee-for-service payments tied to quality or value and $90 \%$ by $2018 .{ }^{40}$ With the increased attention from the ACA on improving outcomes, increasing access to care, and lowering costs, many payment providers are moving away from the fee-for-service model and towards an outcome-based 
payment model. Accountable care organizations (ACOs) are an example of this model, which assume joint accountability between providers and health care organizations. ACOs have incentives under the Medicare Shared Savings Program and Pioneer Model to manage care coordination and other factors affecting readmission rates. There are already examples of ACOs working to reduce readmissions. For example, Kaiser Permanente has shown a reduction in 30-day all-cause readmission rates with their transitional care programs and bundling elements. ${ }^{41}$ Similarly, Colorado's Accountable Care Collaborative, which pilots health care payment and delivery reforms through Medicaid, was able to show $8.6 \%$ fewer hospital readmissions than non-participating Medicaid enrollees within its first year. ${ }^{42}$

ACOs are far from perfect. One concern is the competing incentives between ACOs and the HRRP, which diminishes the impact of both. With limited resources, ACOs must determine which quality measures are most important. Deciding how to prioritize these will require ACOs to balance those most in need versus those most likely to benefit. However, it is anticipated that the incentives between ACOs and HRRP will be complementary and promote the development of interventions that reduce readmissions. On July 3, 2014, CMS issued a proposed rule that would add new quality reporting measures for the Medicare Shared Savings Program, including all-cause unplanned admissions for patients with heart failure and all-cause unplanned admissions for patients with multiple chronic conditions. These additions to the quality reporting standard for the 2015 reporting period will further align the Medicare Shared Savings Program with the HRRP. ${ }^{43}$

\section{Cons}

\section{Potential to Disproportionately Penalize Hospitals Serving Indigent Populations}

Despite the above-mentioned successes, there has been considerable discussion regarding the methodology for calculating excess readmissions. The initial risk-adjustment models did not adjust for socioeconomic status. Several analyses have shown that caring for patients with a lower socioeconomic status puts a hospital at higher risk of incurring penalities. ${ }^{18,44,45}$ This means that the HRRP may be unintentionally taking away resources from hospitals, such as safety-net hospitals, that care for disadvantaged populations. An expert panel convened by the National Quality Forum concluded that not accounting for socioeconomic factors might worsen disparities by penalizing these hospitals. ${ }^{46} \mathrm{In}$ MedPAC's June 2013 Report to Congress, they proposed comparing hospitals to other hospitals with patients of similar socioeconomic status to account for the differences seen in current computation strategies, but the execution of these suggested changes and approaches to risk adjustment have yet to take shape. ${ }^{10,47}$

\section{Potential to Avoid Necessary Readmissions and Increase Mortality}

Much attention has been given to the relationship reported between readmission and mortality measures. A brief report looking at Hospital Compare heart failure data revealed a statistically significant inverse correlation between higher risk-standardized hospital 30-day readmission rates with lower risk-standardized hospital 30-day mortality rates. ${ }^{48} \mathrm{~A}$ subsequent and more detailed analysis of hospital-level risk-standardized readmission and mortality rates demonstrated a modest inverse association between mortality and 
readmission rates in heart failure (correlation coefficient -0.14) and not throughout the entire range of performance; there was no relationship in the acute myocardial infarction and pneumonia rates. ${ }^{49}$

There are several explanations as to why readmission and morality data are inversely related in heart failure. One theory is that some hospitals have a lower threshold for admission and readmission; such hospitals may hospitalize lower-acuity patients (not entirely accounted for by the risk-standardization process), thus making their readmission rates higher and their mortality rates lower. All-cause admission rates have been found to be substantially associated with regional differences in all-cause readmission rates. ${ }^{50}$ An alternative explanation is that hospitals with higher mortality rates have fewer patients to readmit. A high-risk patient who dies in the hospital is not eligible for the readmission measure, and a patient who dies at home shortly after discharge from the index episode of care can never be readmitted. As such, a lower readmission rate could be a consequence of increased mortality.

However, it is the lack of association, not the inverse association, that is perhaps most worthy of attention. There are nearly as many hospitals with concordant (low-low and highhigh) readmission-mortality rates as there are with discordant (high-low and low-high) riskstandardized readmission-mortality rates. This suggests that the domains of readmission and mortality are largely unrelated and that mortality and readmission are the result of somewhat different causes-thus responsive to different interventions. There are plausible reasons that the quality domains of mortality and readmission are distinct. For example, transitions of care interventions and use of hospice are more likely to decrease readmissions; in contrast, code teams and implantation of defibrillators are likely to improve survival. The Hospital Compare website provides both mortality and readmission rates so that both are considered; ${ }^{7}$ however, these measures do not occur at similar rates and they are not of equal importance to patients, so this current side-by-side reporting is imperfect.

\section{Concerns with Root Cause Attribution}

Institutions and providers cite that many readmissions are due to disease progression and patient behaviors. An often-cited example is "Why should my institution be punished if a patient with heart failure leaves the hospital, falls, and breaks her hip?" If this is truly a random event, then on average it should not impact the variability between risk-adjusted institutional rates. However, many events, including hip fracture, may be preventable. Why did the patient fall? Did she undergo a physical therapy evaluation prior to discharge and have appropriate home support? Was she over-diuresed or over-sedated? If incentivized appropriately, care systems can theoretically identify and ameliorate many of these contributing factors, thereby avoiding some unnecessary readmissions. While specific attribution may be difficult to assess for individual cases, risk-standardized summary measures ideally should reflect comprehensive differences in care at the institutional level.

The key question for the outcome measure is not whether an individual readmission is appropriate, but whether hospital-level variations in readmission rates are driven by preventable events. While truly unavoidable readmissions may be common-as few as $12 \%$ of hospitals admissions may truly be preventable ${ }^{51}$ - they are also by their nature relatively 
invariable, and thus should contribute little to differences in risk-standardized readmission rates. The goal of the HRRP is to incentivize processes of care that decrease preventable events and thereby reduce overall readmission rates. Whether the variation in riskstandardized readmission measures primarily reflects important differences in quality or other inappropriate avoidance of readmission remains controversial. The more than two-fold variability in risk-standardized readmission rates between institutions is at face value a strong argument that many readmissions are preventable. A variety of existing interventions to improve the process of hospital transitions (e.g. medication reconciliation, transition coaches, and early follow up) have been shown to decrease overall readmission rates. However, studies have consistently identified a significant minority of readmissions attributable to modifiable etiologies, such as medication errors, non-adherence with recommended therapies, and failure to obtain timely ambulatory follow up. ${ }^{52}$

\section{Arbitrary Time Window}

Decisions about how long past discharge to count a new admission as a readmission have also been criticized.$^{53}$ Readmissions closer to the index hospital discharge are more likely to be related to the quality of inpatient care and transition measures provided. Therefore, 30days was chosen as the window from which to define a readmission, recognizing that there is little difference between a hospitalization that occurs 29 days versus 31 days after the last hospital discharge. Some have suggested weighting the HRRP's penalties according to the timing of readmissions, with greater emphasis on earlier readmissions. Readmissions that occur within the first few days after discharge may reflect poor care coordination or inadequate recognition of post-discharge needs, whereas readmissions four weeks later are more likely to be due to the underlying severity of a patient's disease or events out of the control of the hospital. Under such a scheme, hospitals that care for sicker or more socioeconomically vulnerable populations would be more heavily rewarded for improvements in discharge planning and care coordination to prevent short-term readmissions, with decreased penalties for the fact that their patients may need additional hospital services over the long run. ${ }^{54}$

\section{Controversial Inclusions and Exclusions}

The HRRP includes all unplanned readmissions within 30 days of hospital discharge. In fiscal year 2013, only two procedures were considered planned readmissions and did not impact the readmission measure: 1) acute myocardial infarction patients who later underwent coronary artery bypass graft surgery and 2) acute myocardial infarction patients who later underwent percutaneous coronary intervention. This initial algorithm penalized hospitals for any other planned admission including such procedures as implantable cardioverter-defibrillators (ICD) in heart failure patients. Many planned readmissions, such as ICD placement, often represent high-quality care and should not be counted against hospitals. In response, CMS instituted an algorithm to account for a wider range of planned readmissions starting in fiscal year $2014 .^{9}$

Additionally, there are several categories of patients who are excluded from the readmission measure. For example, patients who are admitted under observation status are excluded. Therefore, many hospitals have developed clinical decision units, which are typically short- 
stay observation areas affiliated with emergency departments designed to care for patients less than 24 hours. While the option to streamline care for patients who are unlikely to require admission is promising, there is little data to support the notion that the use of clinical decision units has reduced acute care utilization, much less readmission rates. Only a small increase in observation stays after hospitalization for acute myocardial infarction, heart failure, and pneumonia has been reported ${ }^{55}$ However, a notable increase in emergency department visits has been seen following heart failure hospitalizations. ${ }^{55}$ Further, with the use of clinical decision units, there are issues of inappropriate patient selection, prolonged observation time, and increased out-of-pocket expenses if patients are eventually admitted to a skilled nursing facility. ${ }^{56} \mathrm{~A}$ hospital also risks removing low-risk patients from the excess readmission denominator with efficient use of a clinical decision unit.

\section{Potential to Overlook the Impact of Hospitalization}

With most efforts focused on reducing readmissions, there is a potential to overlook the stress and vulnerability patients experience. An acquired "post-hospital syndrome" has been described as a period of transient vulnerability, and a time of generalized risk of adverse health outcomes among patients who were recently hospitalized. ${ }^{57}$ During hospitalization, patients experience substantial stress in addition to disruption of their normal physiologic systems. While transitional care measures focus on the period of transfer from inpatient to outpatient, there is less focus on the hospitalization itself. One article suggests methods to reduce the trauma experienced by patients in the hospital, with interventions such as ensuring the patient receives enough rest and nourishment, encouraging activity, eliminating unnecessary testing and procedures, and decreasing random medication modifications. ${ }^{58} \mathrm{~A}$ focus not only on transitional care, but the hospitalization itself may help reduce the postdischarge syndrome, and its potential to increase readmissions. ${ }^{58}$

\section{Recommendations}

The HRRP is a start. As with any quality measure, fairness is critical. Therefore, validation of the risk-standardization process is necessary and ongoing. This must include further inquiry into the nuanced relationship between readmission rates and socioeconomic factors, which are not currently included in risk adjustment methodology. This design was intentional, as additional adjustment for socioeconomic status could mask the existing disparities in care experienced by disadvantaged populations. Conversely, not accounting for the socioeconomic environment disproportionately penalizes hospitals that care for disadvantaged populations, thereby widening disparities in care. Thus, simultaneous reporting of rates that both include and exclude socioeconomic status may be more informative than picking one measure or the other.

Because of limitations in existing administrative data and concerns for coding manipulation, the current approach is forced to lump necessary and unnecessary readmissions together and rely on aggregate rates to reflect potentially preventable events. Improvements in health information technology should facilitate the incorporation of greater clinical detail, allowing for more targeted assessment of preventable readmissions and an improved capacity to risk adjust. Iterative improvements to the outcome measures are vital to their success. 
Additionally, while an advantage of outcomes measures is their reflection of the entire domain of care leading up to an event, CMS does not suggest specific actions to improve them. Providers, hospitals, researchers, and policy makers must then identify deficiencies in processes of care and implement targeted solutions. Programs like the $\mathrm{H} 2 \mathrm{H}$ Initiative, ${ }^{29}$ TARGET:HF, ${ }^{30}$ and Aligning Forces for Quality Network, ${ }^{59}$ which aim to share best practices between institutions and improve transitions of care, represent one important approach. Detailed review of outliers - those hospitals with high-high, high-low, low-high, and low-low risk-standardized mortality and readmission rates_-promises to identify some drivers of variation in outcomes. ${ }^{60}$ Ultimately, a range of investigation is needed to develop more targeted, efficient, patient-centered interventions to improve transitions of care and patient outcomes. The HRRP has drawn attention and energy towards such endeavors.

For now, measuring, reporting, and penalizing risk-standardized readmission rates are an important component of efforts to transform the overall quality and efficiency of care for hospitalized patients. If fairly adjusted for case mix, the variability seen in hospital-level risk-standardized readmission measures should primarily reflect the continuum of care delivery following hospital admission-inpatient, transitional, and early outpatient followup. Moreover, the HRRP focuses energy on the critical and complex process of care transitions. Last, but not least, it helps realign financial incentives to better reward the entire process of care; until 30-day bundled payments or ACOs replace the existing fee-for-service structure, the readmission metrics provide a necessary complement to the IPPS-DRG-based system. The HRRP and similar policies offer a start towards a system that is more integrated, patient-centered, and value-based.

\section{References}

1. Jencks SF, Williams MV, Coleman EA. Rehospitalizations among patients in the Medicare fee-forservice program. N Engl J Med. 2009; 360:1418-1428. [PubMed: 19339721]

2. Bueno H, Ross JS, Wang Y, Chen J, Vidan MT, Normand SL, Curtis JP, Drye EE, Lichtman JH, Keenan PS, Kosiborod M, Krumholz HM. Trends in length of stay and short-term outcomes among Medicare patients hospitalized for heart failure, 1993-2006. JAMA. 2010; 303:2141-2147. [PubMed: 20516414]

3. Krumholz HM, Merrill AR, Schone EM, Schreiner GC, Chen J, Bradley EH, Wang Y, Wang Y, Lin Z, Straube BM, Rapp MT, Normand SL, Drye EE. Patterns of hospital performance in acute myocardial infarction and heart failure 30-day mortality and readmission. Circ Cardiovasc Qual Outcomes. 2009; 2:407-413. [PubMed: 20031870]

4. Zhang W, Watanabe-Galloway S. Ten-year secular trends for congestive heart failure hospitalizations: an analysis of regional differences in the United States. Congest Heart Fail. 2008; 14:266-271. [PubMed: 18983290]

5. Medicare Payment Advisory Commission. [Accessed May 25, 2014] Report to the Congress: promoting greater efficiency in Medicare. http://www.medpac.gov/documents/ jun07_entirereport.pdf

6. Medicare Payment Advisory Commission. [Accessed June 1, 2014] Report to the Congress: reforming the delivery system. http://www.amcp.org/WorkArea/DownloadAsset.aspx?id=1

7. Department of Health and Human Services. [Accessed May 24, 2014] Hospital Compare. www.hospitalcompare.hhs.gov/

8. Centers for Medicare and Medicaid Services. [Accessed May 26, 2014] Acute inpatient PPS. http:// www.cms.gov/Medicare/Medicare-Fee-for-Service-Payment/AcuteInpatientPPS/index.html 
9. Centers for Medicare and Medicaid Services. [Accessed May 26, 2014] Readmissions reduction program. http://www.cms.gov/Medicare/Medicare-Fee-for-Service-Payment/AcuteInpatientPPS/ Readmissions-Reduction-Program.html

10. Medicare Payment Advisory Commission. [Accessed June 20, 2014] Report to the Congress: Medicare and the health care delivery system. http://www.medpac.gov/documents/ Jun13_EntireReport.pdf

11. Centers for Medicare and Medicaid Services. [Accessed June 20, 2014] Affordable Care Act update: implementing Medicare cost savings. http://www.cms.gov/apps/docs/aca-updateimplementing-medicare-costs-savings.pdf

12. Centers for Medicare and Medicaid Services. [Accessed June 20, 2014] Hospital-wide all-cause unplanned readmission (HWR) measure. http://www.qualitynet.org/dcs/ContentServer? $\mathrm{c}=$ Page \&pagename $=$ QnetPublic\%2FPage\%2FQnetTier4\&cid $=1228772504318$

13. Krumholz, HM.; Normand, SLT.; Keenan, PS.; Lin, Z.; Drye, EE.; Bhat, KR.; Wang, YF.; Ross, JS.; Schuur, JD.; Stauffer, BD.; Bernheim, SM.; Epstein, AJ.; Herrin, J.; Federer, JJ.; Mattera, JA.; Wang, Y.; Mulvey, GK.; Schreiner, GC. [Accessed September 3, 2014] Hospital 30-day heart failure readmission measure: methodology. http://www.qualitynet.org/dcs/ContentServer? $\mathrm{c}=$ Page\&pagename=QnetPublic\%2FPage\%2FQnetTier3\&cid=1219069855841

14. Krumholz, HM.; Normand, SLT.; Keenan, PS.; Lin, Z.; Drye, EE.; Bhat, KR.; Wang, YF.; Ross, JS.; Schuur, JD.; Stauffer, BD.; Bernheim, SM.; Epstein, AJ.; Herrin, J.; Federer, JJ.; Mattera, JA.; Wang, Y.; Mulvey, GK.; Schreiner, GC. [Accessed September 3, 2014] Hospital 30-Day acute myocardial infarction readmission measure: methodology. http://www.qualitynet.org/dcs/ ContentServer? $\mathrm{c}=$ Page $\&$ pagename $=$ QnetPublic $\%$ FPage $\% 2$ FQnetTier3\&cid $=1219069855841$

15. Krumholz, HM.; Normand, SLT.; Keenan, PS.; Lin, Z.; Drye, EE.; Bhat, KR.; Wang, YF.; Ross, JS.; Schuur, JD.; Stauffer, BD.; Bernheim, SM.; Epstein, AJ.; Herrin, J.; Federer, JJ.; Mattera, JA.; Wang, Y.; Mulvey, GK.; Schreiner, GC. [Accessed September 3, 2014] Hospital 30-Day pneumonia readmission measure: methodology. http://www.qualitynet.org/dcs/ContentServer? $\mathrm{c}=$ Page \&pagename $=$ QnetPublic\%2FPage $\% 2 F Q$ netTier3\&cid=1219069855841

16. Hospital Engagement Network. [Accessed September 3, 2014] Fiscal year 2013 hospital readmissions reduction program: measure methodology report. http://www.henlearner.org/wpcontent/uploads/2012/03/Hospital-Excess-Readmissions-Metric_Methodology-Report.pdf

17. Kaiser Health News. [Accessed May 25, 2014] Armed with bigger fines, Medicare to punish 2,225 hospitals for excess readmissions. http://kaiserhealthnews.org/news/readmission-penaltiesmedicare-hospitals-year-two/

18. Joynt KE, Jha AK. Characteristics of hospitals receiving penalties under the Hospital Readmissions Reduction Program. JAMA. 2013; 309:342-343. [PubMed: 23340629]

19. Centers for Medicare and Medicaid Services. [Accessed September 5, 2014] FY 2015 final rule data files. http://www.cms.gov/Medicare/Medicare-Fee-for-Service-Payment/AcuteInpatientPPS/ FY2015-IPPS-Final-Rule-Home-Page-Items/FY2015-Final-Rule-Data-Files.html? DLPage $=1 \&$ DLSort $=0 \&$ DLSortDir=ascending

20. Kansagara D, Englander H, Salanitro A, Kagen D, Theobald C, Freeman M, Kripalani S. Risk prediction models for hospital readmission: a systematic review. JAMA. 2011; 306:1688-1698. [PubMed: 22009101]

21. Bradley EH, Curry L, Horwitz LI, Sipsma H, Wang Y, Walsh MN, Goldmann D, White N, Pina IL, Krumholz HM. Hospital strategies associated with 30-day readmission rates for patients with heart failure. Circ Cardiovasc Qual Outcomes. 2013; 6:444-50. [PubMed: 23861483]

22. Centers for Medicare and Medicaid Services. [Accessed May 25, 2014] Community-based care transitions program. http://innovation.cms.gov/initiatives/CCTP/

23. Centers for Medicare and Medicaid Services. [Accessed June 1, 2014] Frequently asked questions about billing Medicare for transitional care management services. http://www.cms.gov/Medicare/ Medicare-Fee-for-Service-Payment/PhysicianFeeSched/Downloads/FAQ-TCMS.pdf

24. Bloink J, Adler KG. Transitional care management services: new codes, new requirements. Fam Pract Manag. 2013; 20:12-17. [PubMed: 23939734]

25. Centers for Medicare and Medicaid Services. [Accessed September 8, 2014] Fact sheets: proposed policy and payment changes to the Medicare physician fee schedule for calendar year 2015. http:// 
www.cms.gov/Newsroom/MediaReleaseDatabase/Fact-sheets/2014-Fact-sheets-items/ 2014-07-03-1.html

26. New York Times. [Accessed September 3, 2014] Medicare to start paying doctors who coordinate care for patients. http://www.nytimes.com/2014/08/17/us/medicare-to-start-paying-doctors-whocoordinate-needs-of-chronically-ill-patients.html?_r=0

27. Krumholz HM, Normand SL, Wang Y. Trends in hospitalizations and outcomes for acute cardiovascular disease and stroke, 1999-2011. Circulation. 2014; 130:966-975. [PubMed: 25135276]

28. United States Department of Health and Human Services. [Accessed May 7, 2014] New HHS data shows major strides made in patient safety, leading to improved care and savings. http:// innovation.cms.gov/Files/reports/patient-safety-results.pdf

29. American College of Cardiology. [Accessed May 25, 2014] Hospital to Home. http:// cvquality.acc.org/en/Initiatives/H2H/About-H2H.aspx

30. American Heart Association. [Accessed June 10, 2014] TARGET:HF. http://www.heart.org/ HEARTORG/HealthcareResearch/TargetHFStroke/TargetHF/TargetHF_UCM_307433_SubHomePage.jsp

31. Institute for Healthcare Improvement. [Accessed September 1, 2014] State action on avoidable readmissions (STAAR). http://www.ihi.org/Engage/Initiatives/Completed/STAAR/Pages/ default.aspx

32. [Accessed August 30, 2014] Interventions to Reduce Acute Care Transfers. INTERACT. http:// interact2.net/about.html

33. Leppin AL, Gionfriddo MR, Kessler M, Brito JP, Mair FS, Gallacher K, Wang Z, Erwin PJ, Sylvester T, Boehmer K, Ting HH, Murad MH, Shippee ND, Montori VM. Preventing 30-day hospital readmissions: a systematic review and meta-analysis of randomized trials. JAMA Intern Med. 2014; 174:1095-1107. [PubMed: 24820131]

34. Krumholz HM, Baker DW, Ashton CM, Dunbar SB, Friesinger GC, Havranek EP, Hlatky MA, Konstam M, Ordin DL, Pina IL, Pitt B, Spertus JA. Evaluating quality of care for patients with heart failure. Circulation. 2000; 101:E122-140. [PubMed: 10736303]

35. Masoudi FA, Rathore SS, Wang Y, Havranek EP, Curtis JP, Foody JM, Krumholz HM. National patterns of use and effectiveness of angiotensin-converting enzyme inhibitors in older patients with heart failure and left ventricular systolic dysfunction. Circulation. 2004; 110:724-731. [PubMed: 15289383]

36. The Joint Comission. [Accessed June 2, 2014] Improving America's hospitals: The Joint Commission's annual report on quality and safety 2011. http://www.jointcommission.org/ assets/1/6/tjc_annual_report_2011_9_13_11_.pdf

37. Fonarow GC, Abraham WT, Albert NM, Stough WG, Gheorghiade M, Greenberg BH, O'Connor CM, Pieper K, Sun JL, Yancy C, Young JB. Association between performance measures and clinical outcomes for patients hospitalized with heart failure. JAMA. 2007; 297:61-70. Investigators O-H and Hospitals. [PubMed: 17200476]

38. Dharmarajan K, Hsieh AF, Lin Z, Bueno H, Ross JS, Horwitz LI, Barreto-Filho JA, Kim N, Bernheim SM, Suter LG, Drye EE, Krumholz HM. Diagnoses and timing of 30-day readmissions after hospitalization for heart failure, acute myocardial infarction, or pneumonia. JAMA. 2013; 309:355-363. [PubMed: 23340637]

39. Eapen ZJ, Reed SD, Li Y, Kociol RD, Armstrong PW, Starling RC, McMurray JJ, Massie BM, Swedberg K, Ezekowitz JA, Fonarow GC, Teerlink JR, Metra M, Whellan DJ, O'Connor CM, Califf RM, Hernandez AF. Do countries or hospitals with longer hospital stays for acute heart failure have lower readmission rates?: Findings from ASCEND-HF. Circ Heart Fail. 2013; 6:727732. [PubMed: 23770519]

40. Burwell SM. Setting value-based payment goals--HHS efforts to improve U.S. health care. N Engl J Med. 2015; 372:897-899. [PubMed: 25622024]

41. Tuso P, Huynh DN, Garofalo L, Lindsay G, Watson HL, Lenaburg DL, Lau H, Florence B, Jones J, Harvey P, Kanter MH. The readmission reduction program of Kaiser Permanente Southern California-knowledge transfer and performance improvement. Perm J. 2013; 17:58-63. [PubMed: 24355891] 
42. Rodin D, Silow-Carroll S. Medicaid payment and delivery reform in Colorado: ACOs at the regional level. The Commonwealth Fund. 2013; 11:1-16.

43. Federal Register. [Accessed September 8, 2014] Revisions to payment policies under the physician fee schedule. https://www.federalregister.gov/articles/2014/07/11/2014-15948/medicare-programrevisions-to-payment-policies-under-the-physician-fee-schedule-clinical-laboratory \&num;h-185

44. Lindenauer PK, Lagu T, Rothberg MB, Avrunin J, Pekow PS, Wang Y, Krumholz HM. Income inequality and 30 day outcomes after acute myocardial infarction, heart failure, and pneumonia: retrospective cohort study. BMJ. 2013; 346:f521. [PubMed: 23412830]

45. Hu J, Gonsahn MD, Nerenz DR. Socioeconomic status and readmissions: evidence from an urban teaching hospital. Health Aff (Milwood). 2014; 33:778-785.

46. National Quality Forum. [Accessed June 20, 2014] Review of draft national quality forum (NQF) report: risk adjustment for socioeconomic status or other sociodemographic factors. http:// www.qualityforum.org/National_Discussion_on_Risk_Adjustment.aspx

47. Eapen ZJ, McCoy LA, Fonarow GC, Yancy CW, Miranda ML, Peterson ED, Califf RM, Hernandez AF. Utility of socioeconomic status in predicting 30-day outcomes after heart failure hospitalization. Circ Heart Fail. 2015

48. Gorodeski EZ, Starling RC, Blackstone EH. Are all readmissions bad readmissions? N Engl J Med. 2010; 363:297-298. [PubMed: 20647209]

49. Krumholz HM, Lin Z, Keenan PS, Chen J, Ross JS, Drye EE, Bernheim SM, Wang Y, Bradley EH, Han LF, Normand SL. Relationship between hospital readmission and mortality rates for patients hospitalized with acute myocardial infarction, heart failure, or pneumonia. JAMA. 2013; 309:587-593. [PubMed: 23403683]

50. Epstein AM, Jha AK, Orav EJ. The relationship between hospital admission rates and rehospitalizations. N Engl J Med. 2011; 365:2287-2295. [PubMed: 22168643]

51. van Walraven C, Bennett C, Jennings A, Austin PC, Forster AJ. Proportion of hospital readmissions deemed avoidable: a systematic review. CMAJ. 2011; 183:E391-402. [PubMed: 21444623]

52. van Walraven C, Jennings A, Taljaard M, Dhalla I, English S, Mulpuru S, Blecker S, Forster AJ. Incidence of potentially avoidable urgent readmissions and their relation to all-cause urgent readmissions. CMAJ. 2011; 183:E1067-1072. [PubMed: 21859870]

53. Vaduganathan M, Bonow RO, Gheorghiade M. Thirty-day readmissions: the clock is ticking. JAMA. 2013; 309:345-346. [PubMed: 23340632]

54. Joynt KE, Jha AK. Thirty-day readmissions--truth and consequences. N Engl J Med. 2012; 366:1366-1369. [PubMed: 22455752]

55. Centers for Medicare and Medicaid Services. [Accessed September 3, 2014] Medicare hospital quality chartbook: performance report on outcomes measures. http://www.cms.gov/Medicare/ Quality-Initiatives-Patient-Assessment-Instruments/HospitalQualityInits/Downloads/-MedicareHospital-Quality-Chartbook-2013.pdf

56. Feng Z, Wright B, Mor V. Sharp rise in Medicare enrollees being held in hospitals for observation raises concerns about causes and consequences. Health Aff (Milwood). 2012; 31:1251-1259.

57. Krumholz HM. Post-hospital syndrome--an acquired, transient condition of generalized risk. N Engl J Med. 2013; 368:100-102. [PubMed: 23301730]

58. Detsky AS, Krumholz HM. Reducing the trauma of hospitalization. JAMA. 2014; 311:2169-2170. [PubMed: 24788549]

59. Robert Wood Johnson Foundation. [Accessed June 2, 2014] Aligning forces for quality. http:// forces4quality.org/node/3404

60. Bradley EH, Herrin J, Wang Y, McNamara RL, Radford MJ, Magid DJ, Canto JG, Blaney M, Krumholz HM. Door-to-drug and door-to-balloon times: where can we improve? Time to reperfusion therapy in patients with ST-segment elevation myocardial infarction (STEMI). Am Heart J. 2006; 151:1281-1287. [PubMed: 16781237] 


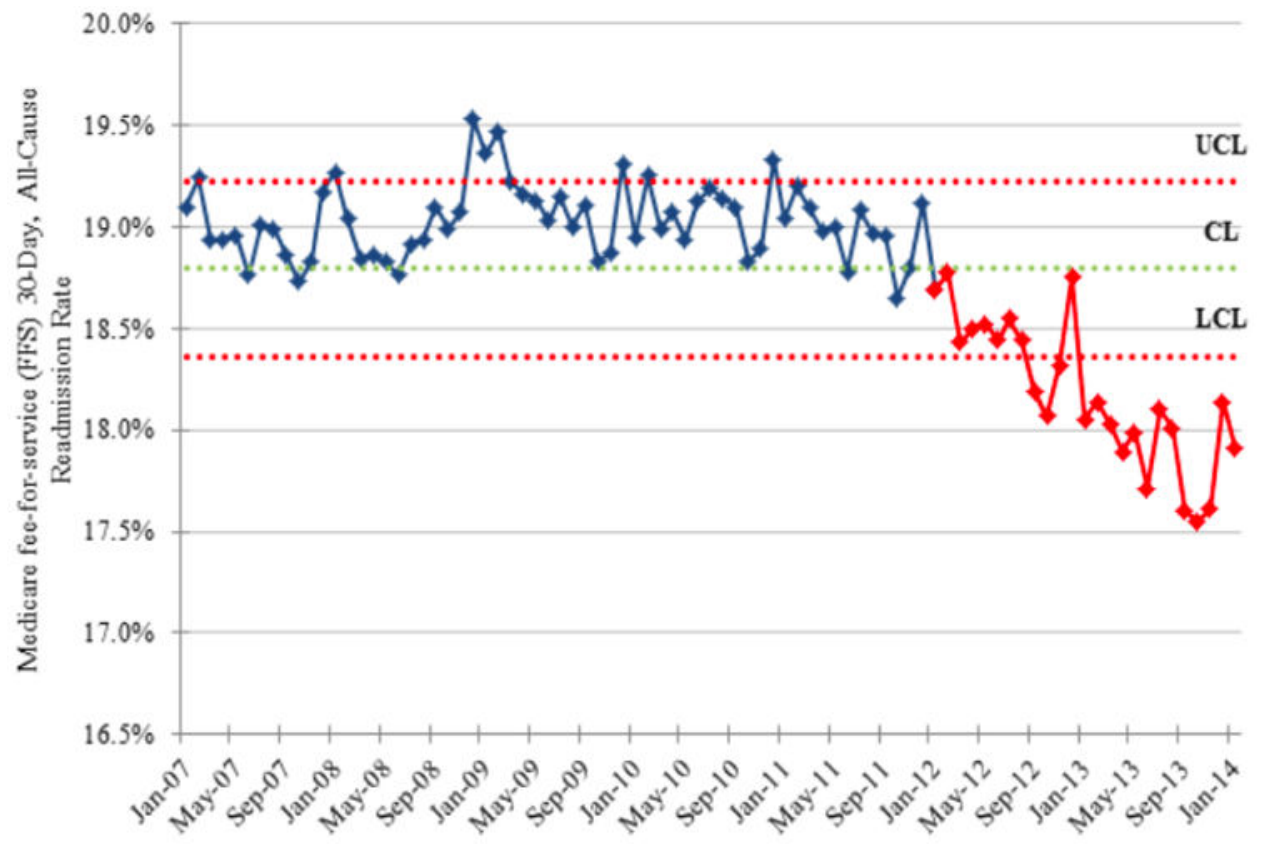

Figure.

Medicare fee-for-service, all-cause, 30-day readmission rates. 